\title{
Antiviral activity of four types of bioflavonoid against dengue virus type-2
}

\author{
Keivan Zandi', Boon-Teong Teoh', Sing-Sin Sam ${ }^{1}$, Pooi-Fong Wong ${ }^{2}$, Mohd Rais Mustafa ${ }^{2}$ and Sazaly AbuBakar ${ }^{\text {* }}$
}

\begin{abstract}
Background: Dengue is a major mosquito-borne disease currently with no effective antiviral or vaccine available. Effort to find antivirals for it has focused on bioflavonoids, a plant-derived polyphenolic compounds with many potential health benefits. In the present study, antiviral activity of four types of bioflavonoid against dengue virus type -2 (DENV-2) in Vero cell was evaluated. Anti-dengue activity of these compounds was determined at different stages of DENV-2 infection and replication cycle. DENV replication was measured by Foci Forming Unit Reduction Assay (FFURA) and quantitative RT-PCR. Selectivity Index value (SI) was determined as the ratio of cytotoxic concentration $50\left(\mathrm{CC}_{50}\right)$ to inhibitory concentration $50\left(\mathrm{IC}_{50}\right)$ for each compound.

Results: The half maximal inhibitory concentration $\left(I_{50}\right)$ of quercetin against dengue virus was $35.7 \mu \mathrm{g} \mathrm{mL}^{-1}$ when it was used after virus adsorption to the cells. The $I_{50}$ decreased to $28.9 \mathrm{\mu g} \mathrm{mL}^{-1}$ when the cells were treated continuously for $5 \mathrm{~h}$ before virus infection and up to 4 days post-infection. The SI values for quercetin were 7.07 and $8.74 \mathrm{\mu g} \mathrm{mL}^{-1}$, respectively, the highest compared to all bioflavonoids studied. Naringin only exhibited antiadsorption effects against DENV-2 with $\mathrm{IC}_{50}=168.2 \mu \mathrm{g} \mathrm{mL} \mathrm{L}^{-1}$ and its related SI was 1.3. Daidzein showed a weak anti-dengue activity with $\mathrm{IC}_{50}=142.6 \mathrm{\mu g} \mathrm{mL}^{-1}$ when the DENV-2 infected cells were treated after virus adsorption. The SI value for this compound was 1.03. Hesperetin did not exhibit any antiviral activity against DENV-2. The findings obtained from Foci Forming Unit Reduction Assay (FFURA) were corroborated by findings of the qRT-PCR assays. Quercetin and daidzein $\left(50 \mu \mathrm{g} \mathrm{mL}^{-1}\right)$ reduced DENV-2 RNA levels by $67 \%$ and $25 \%$, respectively. There was no significant inhibition of DENV-2 RNA levels with naringin and hesperetin.

Conclusion: Results from the study suggest that only quercetin demonstrated significant anti-DENV-2 inhibitory activities. Other bioflavonoids, including daidzein, naringin and hesperetin showed minimal to no significant inhibition of DENV-2 virus replication. These findings, together with those previously reported suggest that select group of bioflavonoids including quercetin and fisetin, exhibited significant inhibitory activities against dengue virus. This group of flavonoids, flavonol, could be investigated further to discover the common mechanisms of inhibition of dengue virus replication.
\end{abstract}

Keywords: Antiviral, Dengue virus, Flavonoid, Quercetin, Naringin, Daidzein, Hesperetin

\section{Background}

Dengue virus (DENV) is a member of the genus flavivirus of the Flaviviridae family. It is a significant human pathogen which causes a wide spectrum of clinical illnesses ranging from a silent or mild febrile infection, self-limited dengue fever (DF) to the severe dengue hemorrhagic fever (DHF) and dengue shock syndrome

\footnotetext{
* Correspondence: sazaly@um.edu.my

${ }^{1}$ Tropical Infectious Disease Research and Education Center (TIDREC), Department of Medical Microbiology, Faculty of Medicine, University of Malaya, Kuala Lumpur, Malaysia

Full list of author information is available at the end of the article
}

(DSS). There are four dengue virus genotypes, DENV-1, DENV-2, DENV-3 and DENV-4 which are transmitted to humans mainly by two species of mosquitoes, Aedes agypti and Aedes Albopictus [1]. All four DENV can cause dengue. To date there are no effective vaccine or antiviral treatment for dengue. Dengue patients are usually supportively-treated until they recover without any specific treatment measures. Several studies have shown that the level of viremia correlates with the severity of disease with high viremia often seen in severe dengue. Hence, antivirals that can reduce the level of
C Biomed Central

(c) 2011 Zandi et al; licensee BioMed Central Ltd This is an Open Access article distributed under the terms of the Creative Commons Attribution License (http://creativecommons.org/licenses/by/2.0), which permits unrestricted use, distribution, and reproduction in any medium, provided the original work is properly cited. 
viremia or the viremic phase could possibly reduce the severity of dengue.

Plants and plant's derived compounds remain an important source for the discovery and the development of new antiviral drugs because of their expected low side effects and their high accessibility in the nature [2-4]. There have been numerous reports on the antiviral activity of various phytochemicals against dengue viruses and these include various flavonoids [5-8]. Flavonoids are basically low molecular weight phenolic compounds found widely in different kinds of plants. Different types of flavonoids can be found in fruits, roots, nuts, seeds, bark, steams and flowers of plants. These include quercetin which can be found in some foods and fruits such as green and black tea, apple, onion, citrus, tomato and some other plants $[9,10]$. Antiviral activities of various other flavonoids have also been reported against some viruses including human cytomegalovirus (HCMV), HSV-1, HSV-2 and some types of human adenoviruses [11-13].

In the present study, we are interested to examine the anti-dengue virus properties of quercetin, hesperetin, naringin and daidzein. Hesperetin is a flavonone and its glycoside form, hesperidin is water soluble and it could be found in various citrus fruits. After ingestion of hesperidin, its sugar moiety is released from the backbone of this compound and the aglycone form known as hesperetin can be released. In vitro antiviral activities of hesperetin have been reported against some RNA viruses [14-16]. Naringin on the other hand, is a flavonone glycoside found abundantly in grapefruit juice. Antiviral activity of naringin were reported against HSV-1 and HSV-2 but this finding remains controversial [12,17]. Daidzein is an isoflavone found in soybeans and its antiviral activity against influenza viruses has been reported [18]. Currently, there is no published data on the possible anti-dengue virus activities of quercetin, hesperetin, naringin and daidzein. Therefore, in this study we evaluated these compounds activities on DENV-2 (NGC strain) replication in cell culture system. The effects of each compound were evaluated against different stages of dengue virus replication including virus adsorption, intracellular replication and direct virucidal activities.

\section{Methods}

Bioflavonoids

Four different types of bioflavonoid, quercetin, naringin, hesperetin (Sigma-Aldrich, St. Louis, MO, USA) and daidzein (Indofine Chemical Co. Inc., Hillsborough, NJ, USA) were evaluated for their potential activities against dengue virus replication. Dimethyl sulfoxide (DMSO) (Sigma-Aldrich, St. Louis, MO, USA) was used to dissolve the lyophilized form of compounds and prepared stock solutions $\left(20 \mathrm{mg} \mathrm{mL}^{-1}\right)$ were stored at $-20 \mathrm{C}$. Stock solution was diluted using cell culture medium and sterilized by a syringe filter with $0.2 \mu \mathrm{m}$ pore size (Millipore, MA, USA) right before each experiment.

\section{Cells and virus}

C6/36 mosquito cell line derived from Aedes albopictus and Vero (African green monkey kidney) cell line were used in this study. Both cell lines were maintained and propagated in Eagle's Minimum Essential Medium (EMEM) (Gibco, NY, USA) containing 10\% fetal bovine serum (Gibco, NY, USA). Cultured C6/36 and Vero cells were incubated at $28 \mathrm{C}$ and $37 \mathrm{C}$, respectively in $5 \% \mathrm{CO}_{2}$ humidified chamber. At the time of virus propagation, serum concentration was reduced to $2 \%$. Dengue virus type-2 (DENV-2) New Guinea C strain (NGC) was propagated using $\mathrm{C} 6 / 36$ cell line and harvested after CPE presentation on day seven post-infection. After titration, viral stock was stored at $-70 \mathrm{C}$. Cell lines and virus were provided by Virology laboratory of the Tropical Infectious Disease Research and Education Center, Faculty of Medicine, University of Malaya (Kuala Lumpur, Malaysia).

\section{In vitro cytotoxicity assay}

MTT assay was performed following the manufacturer's instructions (Promega, WI, USA). Briefly, confluent Vero cells in 96-well cell culture microplates were treated with different concentrations of each compound in triplicate. The treated cells were incubated for four days at $37 \mathrm{C}$ followed by the addition of $15 \mu \mathrm{l}$ of MTT solution to each well. The microplate was incubated at $37 \mathrm{C}$ for $4 \mathrm{~h}$. Then, $100 \mu \mathrm{l}$ of the solubilisation/stopping solution was added to each well. The optical density (OD) of wells was measured at 570 using 96-well plate reader (TECAN, Mannendorf, Switzerland). Dose-response curves were plotted using Graph Pad Prism 5 (Graph Pad Software Inc., San Diego, CA).

\section{Pretreatment of cells with bioflavonoids}

In order to determine the prophylactic anti-dengue activity of compounds, different concentrations of compounds were added to the Vero monolayer cells in triplicate at different times, $5 \mathrm{~h}$ before virus infection. After $5 \mathrm{~h}$ of pre-infection treatment, the cells were washed twice with sterile PBS and then 200 FFU of DENV-2 was inoculated to the cells and incubated at 37 $\mathrm{C}$ for $1 \mathrm{~h}$. To determine the effects of continuous treatment, different concentrations of each compound were added to the Vero cells, $5 \mathrm{~h}$ pre-infection and continuously for 4 days post-infection.

In a separate experiment, antiviral activity of compounds against intracellular replication of DENV-2 was performed by inoculation of $200 \mathrm{FFU}$ of virus to each 
well in triplicate. After adsorption of virus to the cells for $1 \mathrm{~h}$ at $37 \mathrm{C}$, the cells were washed with PBS to eliminate the unabsorbed viruses. Then, different concentrations of each compound were added to the cells, followed by 4 days of incubation at $37 \mathrm{C}$. DENV RNA was then quantified using quantitative RT-PCR. In another experiment, Vero cells at $80 \%$ confluency were infected with $200 \mathrm{FFU}$ of DENV-2 in the presence or absence of different concentrations of each compound. The microplate was kept at $37 \mathrm{C}$ for $1 \mathrm{~h}$ for virus adsorption. Then the cells were washed two times by sterile PBS and incubated at $37 \mathrm{C}$ for four days.

Direct virucidal effects of the bioflavonoids were investigated by incubating DENV-2 suspension containing $200 \mathrm{FFU}$ with an equal volume of the different concentrations of each compound for $2 \mathrm{~h}$ at $37 \mathrm{C}$. Then, Vero cells were infected with the treated viral suspension in triplicate. After $1 \mathrm{~h}$ adsorption at $37 \mathrm{C}$, cells were washed twice with PBS in order to remove unabsorbed viruses. Then the microplate was incubated at 37 $\mathrm{C}$ for 4 days.

\section{Antiviral activity assay}

Antiviral activities of the tested compounds were evaluated by measuring the reduction in number of viral foci. Briefly, confluent monolayers of Vero cells were prepared in 24 wells cell culture microplate. Then the infected cells treated using different procedures described above were overlaid with $1.5 \%$ of Carboxy Methyl Cellulose (CMC) (Sigma-Aldrich, St. Louis, MO, USA) containing EMEM. Viral foci were visualized using peroxidase-based foci staining assay four days post infection [19]. The numbers of DENV-2 foci were counted using a stereomicroscope and the titer of virus was expressed as Foci-Forming-Unit (FFU). The percentage of viral foci reduction (RF \%) compared with controls was calculated as follows: $\operatorname{RF}(\%)=(C-T) \times 100 / C$. Where, $C$ is the mean of the number of foci for negative control well (without compound) and $\mathrm{T}$ is the mean of the number of foci in treated wells. Reduction in the number of viral foci was further verified using quantitative RT-PCR (qRT-PCR).

\section{Dengue virus quantitative RT-PCR (qRT-PCR)}

Quantitative RT-PCR was performed to determine the effects of bioflavonoids on DENV replication by quantifying DENV-2 genomic RNA copies based on a method described previously with some modifications [20]. Briefly, intracellular and extracellular DENV-2 RNAs were harvested from the DENV-infected Vero cells. Viral RNA was extracted using two types of RNA extraction kits (QIAamp Viral RNA mini kit and RNeasy mini kit) (Qiagen, Hilden, Germany). Quantitative RTPCR assay was performed by adding $1 \mu$ l of extracted
DENV RNA to the SensiMix SYBR green reagent (Quantace, Watford, United Kingdom) which contained $7.4 \mu \mathrm{lddH} 2 \mathrm{O}, 10 \mu \mathrm{l} 2 \mathrm{X}$ SensiMix One-Step, $0.4 \mu \mathrm{l} 50 \mathrm{X}$ SYBR Green solution, 10 units of RNAse Inhibitor, 50 pmol of forward (DNF) and also reverse (D2R) primers [21]. All samples were assayed in triplicate. The amplifications were performed using the DNA Engine Opticon system (MJ Research/Bio-Rad, Hercules, CA) with the following thermal conditions: reverse transcription at $50^{\circ} \mathrm{C}$ for $30 \mathrm{~min}$, initial denaturation at $95^{\circ} \mathrm{C}$ for $10 \mathrm{~min}$, followed by 45 cycles of $95^{\circ} \mathrm{C}$ for $15 \mathrm{sec}, 59^{\circ} \mathrm{C}$ for $30 \mathrm{sec}$ and $72^{\circ} \mathrm{C}$ for $30 \mathrm{sec}$. Melting curve analysis was subsequently performed at temperature from $60^{\circ} \mathrm{C}$ to $98^{\circ} \mathrm{C}$ to verify the assay specificity. For absolute quantitation of the viral RNA, a standard curve was established with a serially diluted RNA extracted from DENV-2 stock with known titer.

\section{Statistical analysis}

Graph Pad Prism for Windows, version 5 (Graph Pad Software Inc., San Diego, CA, 2005) was used to determine the cytotoxic concentration $50\left(\mathrm{CC}_{50}\right)$ and inhibitory concentration $50\left(\mathrm{IC}_{50}\right)$ values of bioflavonoids. Selectivity Index value (SI) was determined as the ratio of $\mathrm{CC}_{50}$ to $\mathrm{IC}_{50}$ for each compound.

\section{Results}

\section{Cytotoxicity of bioflavonoids}

MTT assay was used to determine cytotoxicity of each bioflavonoid on Vero cells and the $\mathrm{CC}_{50}$ value of each compound was calculated (Table 1 and Figure 1). Vero cells were treated by bioflavonoids for 4 days which was the same duration used for antiviral activity assay. Results showed that hesperetin with $\mathrm{CC}_{50}=110.3 \pm$ $0.32 \mu \mathrm{g} \mathrm{mL} \mathrm{m}^{-1}$ is the most cytotoxic compound for Vero cells compared to the other tested compounds. Quercetin and daidzein showed lower toxicity against Vero cells at $\mathrm{CC}_{50} 252.6 \pm 0.17$ and $147.8 \pm 0.31 \mu \mathrm{g} \mathrm{mL} \mathrm{L}^{-1}$, respectively. Meanwhile, naringin with $\mathrm{CC}_{50}=230.3 \pm$ $0.19 \mu \mathrm{g} \mathrm{mL}{ }^{-1}$ showed the least cytotoxic effects against Vero cells. Cells treated with vehicle control, 1\% DMSO did not show any cytotoxicity against Vero cells.

Table 1 Cytotoxicity assays were performed using the MTT assay method described in text

\begin{tabular}{cc}
\hline Flavonoids & $\mathrm{CC}_{\mathbf{5 0}}\left(\boldsymbol{\mu g} \mathbf{~ m L}^{-\mathbf{1}}\right)$ \\
\hline Quercetin & $252.6 \pm 0.17$ \\
\hline Daidzein & $147.8 \pm 0.31$ \\
\hline Naringin & $230.3 \pm 0.19$ \\
\hline Hesperetin & $110.3 \pm 0.32$
\end{tabular}

The $\mathrm{CC}_{50}$ of bioflavonoids were calculated using Graph Pad Prism Version 5 (Graph Pad Software Inc., San Diego, CA.). Results are presented as mean \pm SD of triplicate experiment. 


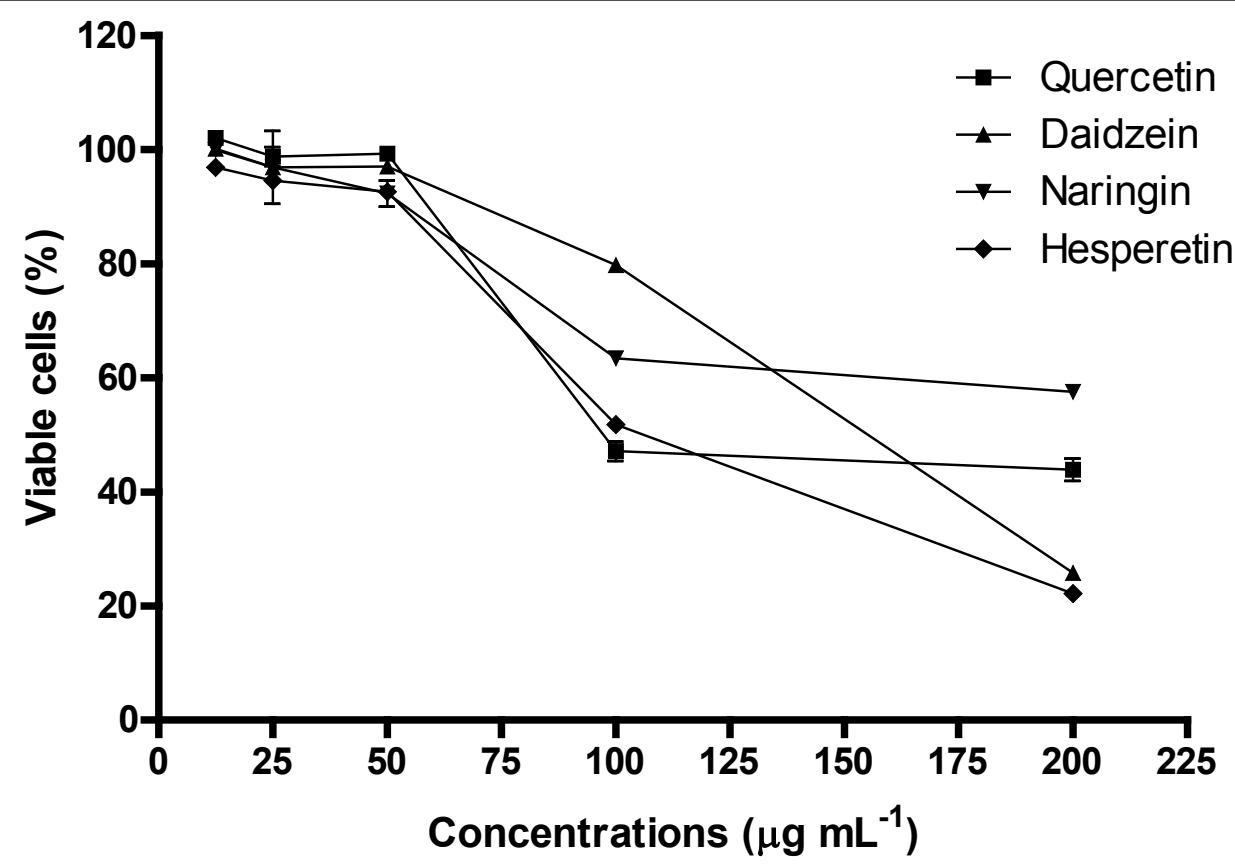

Figure 1 Cytotoxicity of flavonoids against Vero cells. MTT assay was performed on Vero cells after $96 \mathrm{~h}$ treatment with increasing concentrations of the flavonoids. Results are presented as percentage of cell viability from triplicate assays.

\section{Antiviral activity of bioflavonoids}

Results of Vero cells pre-treatment with the compounds showed that $50 \mu \mathrm{g} \mathrm{mL}{ }^{-1}$ of quercetin could decrease the number of DENV-2 foci by $14 \% \pm 1.5$ when compared to the non-treated cells. However, there was no prophylactic activity against DENV-2 from other compounds (data not shown). In post-adsorption assay, quercetin exhibited the most significant antiviral activity against DENV-2 amongst the bioflavonoids tested with $\mathrm{IC}_{50}=$ $35.7 \mu \mathrm{g} \mathrm{mL}^{-1}$ (Figure 2a). The SI value for quercetin in post-adsorption assay was relatively high at 7.07. It was also demonstrated that the level of DENV-2 specific RNA production in the presence of $50 \mu \mathrm{g} \mathrm{mL}^{-1}$ of quercetin decreased by more than $67 \% \pm 1$ when compared to the non-treated infected cells (Figure 2b). Daidzein showed very weak anti-dengue activity with $\mathrm{IC}_{50}=142.6$ $\mu \mathrm{g} \mathrm{mL}{ }^{-1}$ when the infected cells were treated after DENV-2 adsorption (Figure 2a). Its related SI value was 1.03. The levels of DENV-2 RNA production in the presence of $50 \mu \mathrm{g} \mathrm{mL}^{-1}$ of daidzein decreased by only $25.3 \% \pm 0.7$ when compared to the non-treated infected cells (Figure 2b). Naringin and hesperetin did not exhibit any anti-dengue activity when they were used after adsorption of DENV-2 to the Vero cells (Figure 2).

Although there was no significant direct virucidal activity against DENV-2 by quercetin, continuous treatment of cells from $5 \mathrm{~h}$ before virus infection up to 4 days post-infection exhibited anti-dengue activity with $\mathrm{IC}_{50}=28.9 \mu \mathrm{g} \mathrm{mL}^{-1}$ (Figure 3a). The SI value for continuous treatment with quercetin was 8.74 and higher than the SI value (7.07) for post-adsorption assay. In addition, the level DENV-2 RNA production decreased by more than $75.7 \% \pm 1.57$ when Vero cells were treated with $50 \mu \mathrm{g} \mathrm{mL} \mathrm{m}^{-1}$ of quercetin, $5 \mathrm{~h}$ before virus infection and up to 4 days post infection (Figure $3 \mathrm{~b})$. There was no significant change in the antiviral activity of daidzein when cells were treated continuously from $5 \mathrm{~h}$ before virus infection up to 4 days post infection comparing to its anti-dengue activity for postadsorption treatment (Figure 1). No significant antiviral activity for naringin and hesperetin was observed for the continuous treatment against DENV-2 (Figure 2). However, naringin exhibited anti-adsorption activity when it was added to the cells at the same time of virus adsorption. The $\mathrm{IC}_{50}$ value for naringin was $168.2 \mu \mathrm{g} \mathrm{mL}^{-1}$ and its related SI was 1.3 (Figure 3a). There was a reduction of $25.8 \% \pm 0.76$ in DENV-2 RNA production in the presence of $50 \mu \mathrm{g} \mathrm{mL}^{-1}$ of naringin (Figure $4 \mathrm{a}$ ).

The majority of the viral foci in cells treated with 50 $\mu \mathrm{g} / \mathrm{ml}$ quercetin appeared smaller, less intensely stained and more diffused within the focus (Figure 5b), compared to the larger, well-defined and more intensely stained foci of the untreated cells (Figure 5a). This observation is consistent with the reduction of the percentage of foci and RNA copy number.

Results from the direct virucidal activity evaluation of each compound showed that there was no extracellular inhibitory activity against DENV-2 for all the tested 


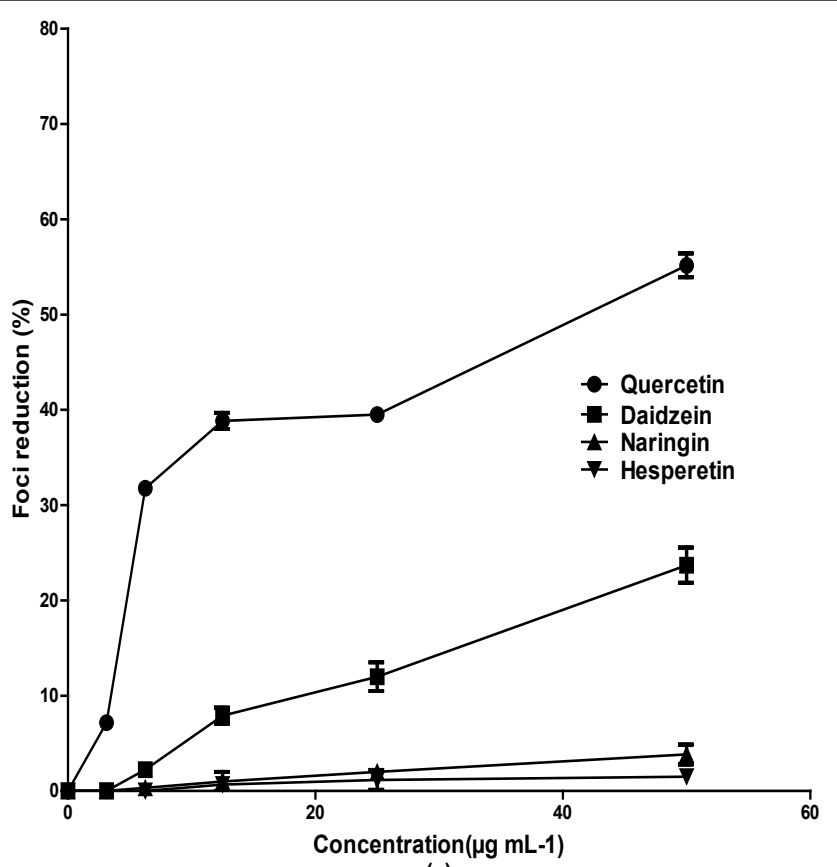

(a)

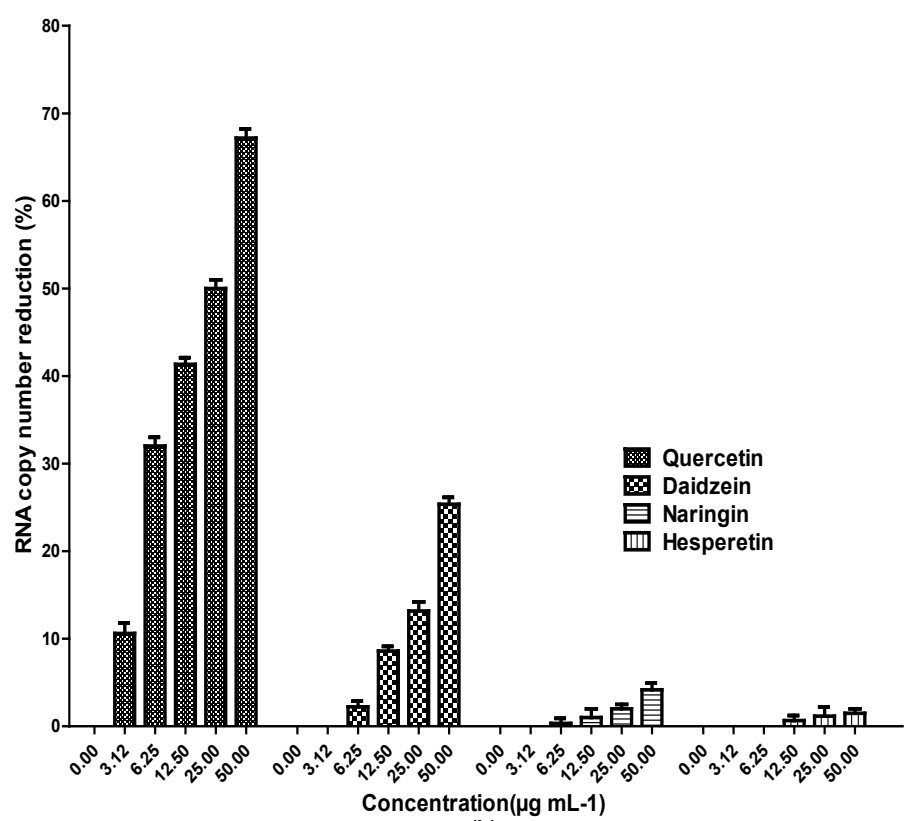

(b)

Figure 2 Anti-viral assay of flavonoids against DENV-2 intracellular replication. Foci forming unit reduction assay (FFURA) was used to evaluate the in vitro anti-dengue virus activities of flavonoids after viral adsorption (a) and the respective DENV-2 RNA copies were quantified using qRT-PCR (b). The percentages of foci reduction (\% RF) were calculated relative to the untreated controls maintained in parallel. Data from triplicate assays were plotted using Graph Pad Prism Version 5 (Graph Pad Software Inc., San Diego, CA. USA).

compounds. Similarly, qRT-PCR analysis showed that there was no significant decrease in copy number of DENV-2 RNA following direct treatment of DENV-2 with the different concentrations of each compound (data not shown).

\section{Discussion}

Recent studies have shown that flavonoids such as glabranine and 7-O-Methyle glabranine exhibited significant antiviral activities against dengue virus. In vitro treatment of infected cells with these flavonoids resulted in 


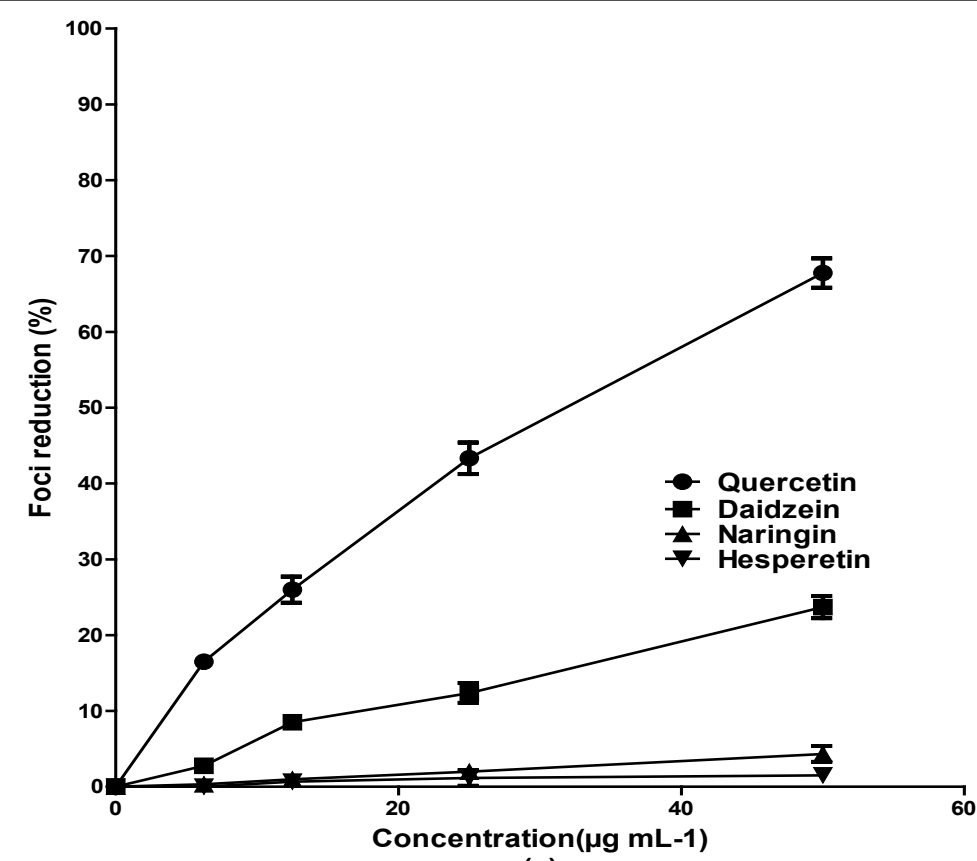

(a)

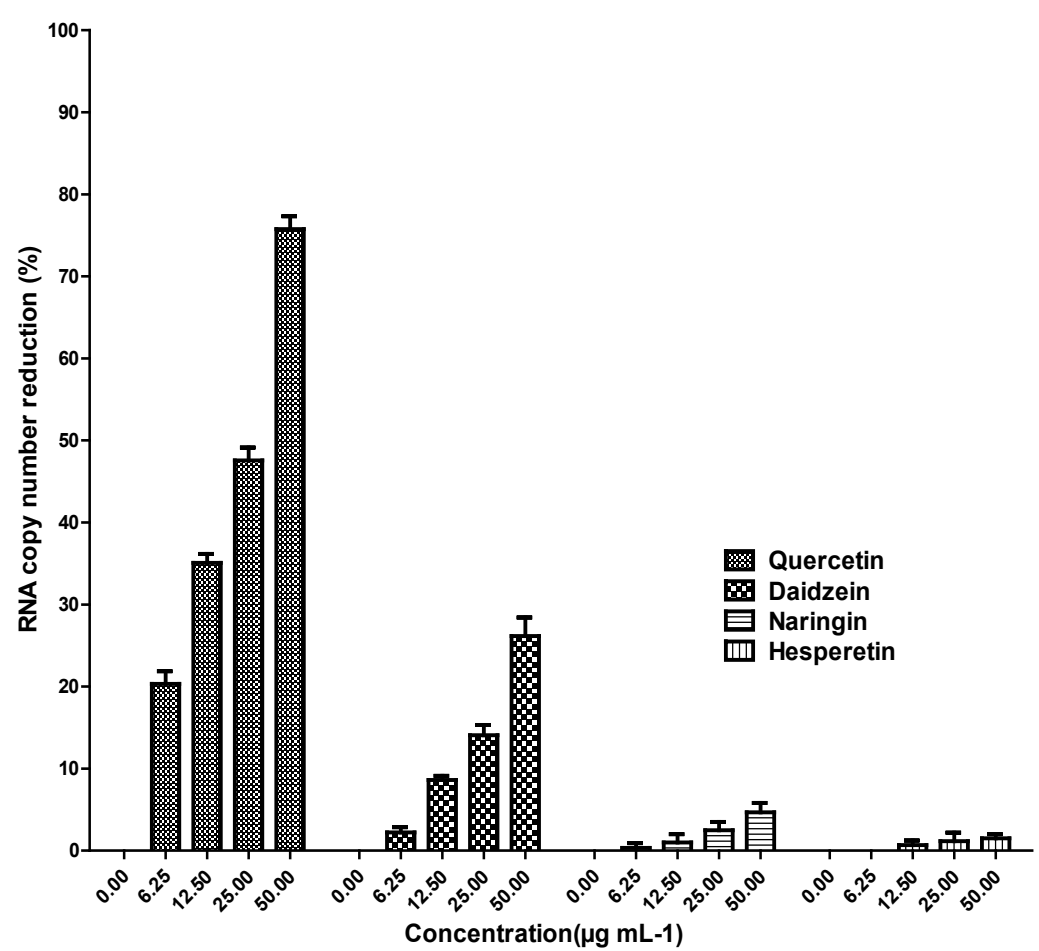

(b)

Figure 3 Anti-viral effects of continuous treatment with flavonoids against DENV-2 replication. Foci forming unit reduction assay (FFURA) was used to evaluate the in vitro anti-dengue virus activities of the flavonoids. Cells were treated with the flavonoids at $5 \mathrm{~h}$ before infection and continuously treated with fresh flavonoids upto 4 days post infection (a). The respective DENV-2 RNA copy numbers were quantified using qRTPCR (b). The percentages of foci reduction (\% RF) were obtained by comparing against untreated controls maintained in parallel. Data from triplicate experiments were plotted using Graph Pad Prism Version 5 (Graph Pad Software Inc., San Diego, CA). 


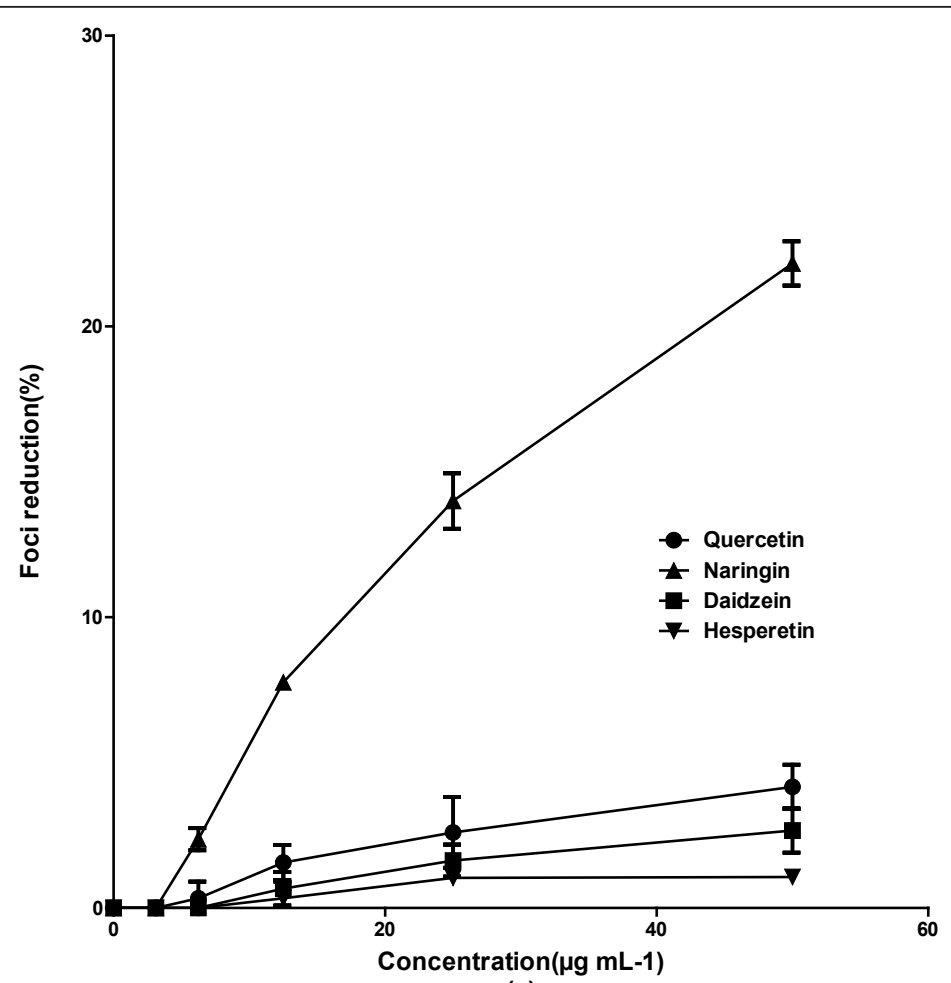

(a)

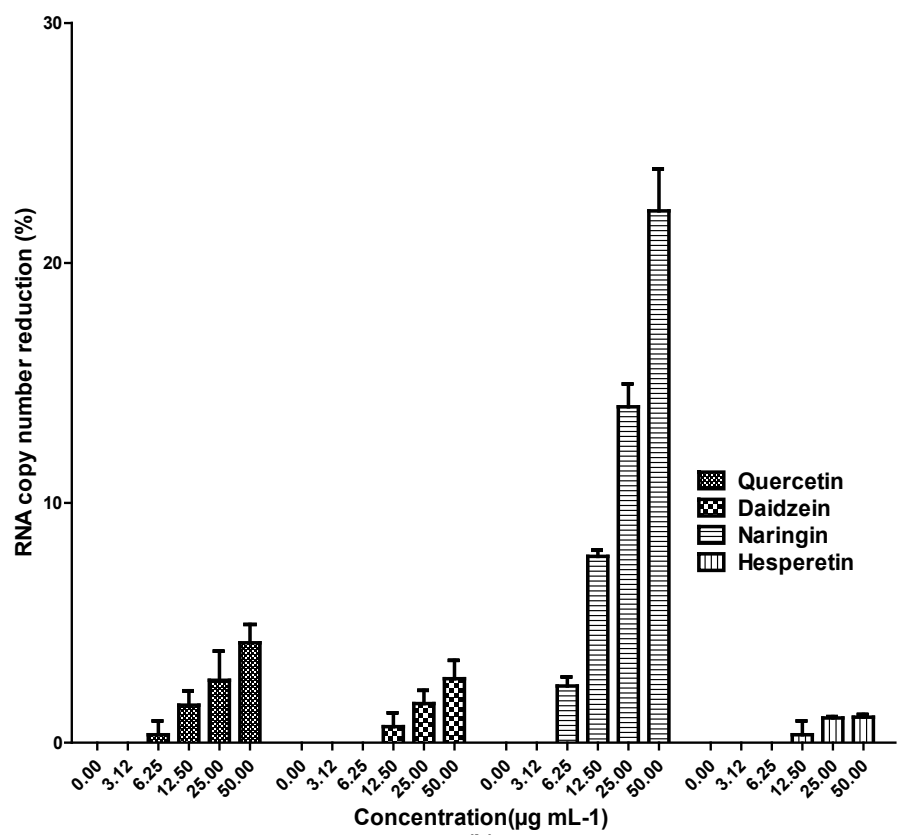

(b)

Figure 4 Anti-adsorption activity of flavonoids against DENV-2. Flavonoids were added directly to virus inocula for $2 \mathrm{~h}$ at $37 \mathrm{C}$. The inocula were used to infect Vero cell monolayers in 24 wells cell culture microplates. The reduction in foci forming unit was calculated relative to the controls maintained in parallel (a) and the respective DENV-2 RNA copy numbers were quantified using qRT-PCR (b). Data from triplicate experiments were plotted using Graph Pad Prism Version 5 (Graph Pad Software Inc., San Diego, CA). 

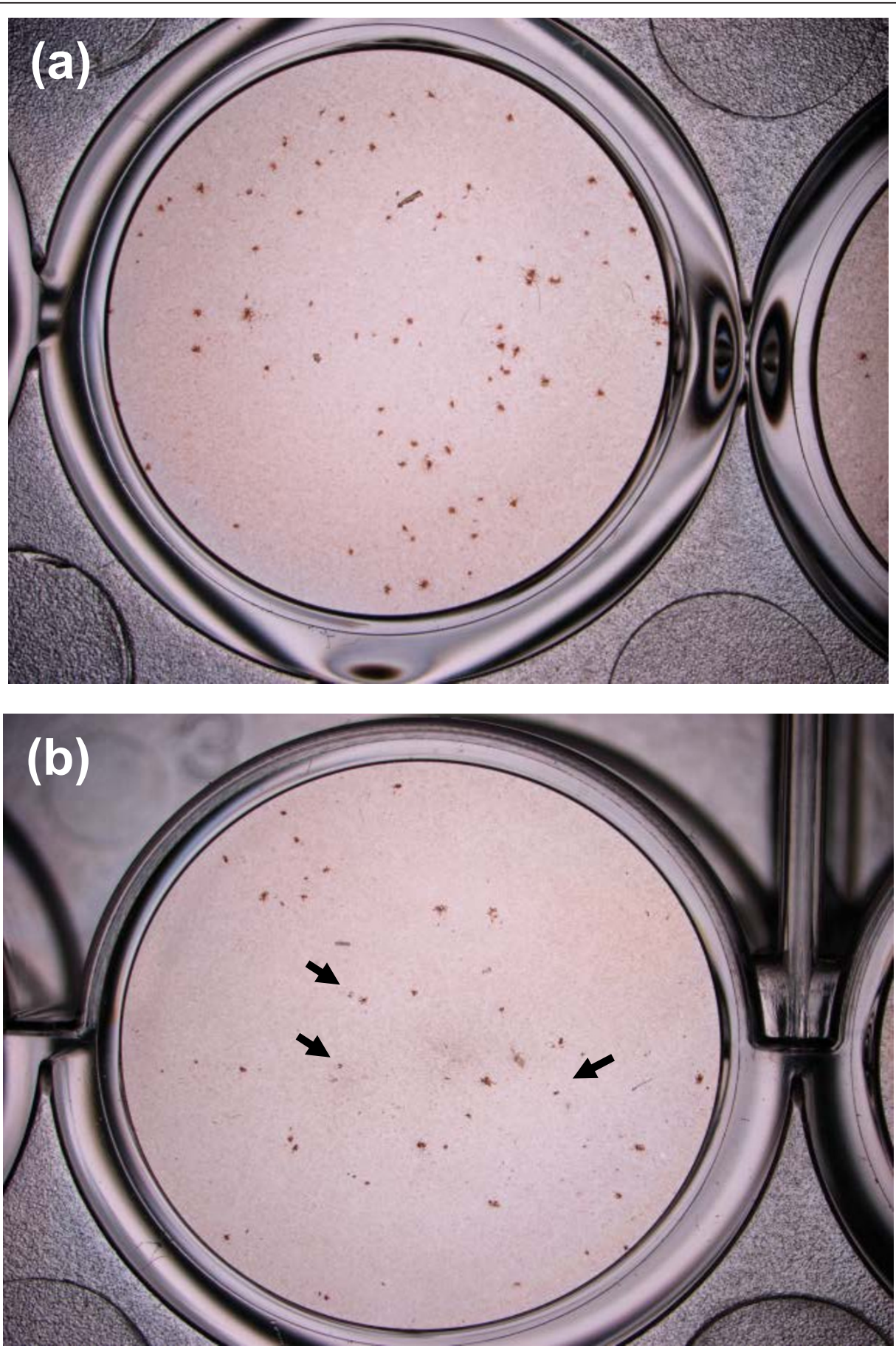

Figure 5 Foci size reduction in DENV-infected cell treated with quercetin. Foci forming unit reduction assay (FFURA) was used to evaluate the in vitro anti-dengue virus activity of quercetin after viral adsorption. Foci of the non-treated infected cells (a) compared with foci in cells treated with quercetin $(50 \mathrm{\mu g} / \mathrm{ml})$ postadsorption (b). Arrows indicate foci which are more diffused, less intensely stained and smaller than the foci in non-treated cells.

the reduction of intracellular replication of dengue virus by $76.9 \%$ and $75 \%$ following treatment with $25 \mu \mathrm{M}$ of glabranine and 7-O-Methyle glabranine, respectively [22]. Similarly, other synthetic flavonoid derivatives also showed antiviral activity in HepG2 cells [23]. Whereas, pinostrobin was reported to inhibit DENV-2 NS2B/NS3 protease an enzyme important in dengue virus replication in an in vitro study [24]. These suggest that 
flavonoids as a group could consist of select compounds that possesses inhibitory activities against DENV. To investigate which of the many flavonoids could affect DENV infection, in the present study, we examined the potential effects of quercetin, naringin, hesperetin and daidzein on dengue virus infection of Vero cells. Unlike the previous studies which evaluated antiviral activity of flavonoids only after adsorption of virus to the cells $[22,23]$, the present study evaluated antiviral activity by different treatment procedures tailored to determine prophylactic, post adsorption, continuous treatment and direct virucidal activities of quercetin, naringin, daidzein and hesperetin.

Our findings demonstrated that quercetin was the only compound among all tested flavonoids that consistently showed significant antiviral activity against DENV-2 in Vero cells. Selectivity indices for quercetin when the infected cells were treated or when uninfected cells were treated continuously $5 \mathrm{~h}$ before infection until 4 days post-infection were 7.07 and 8.74 , respectively. The noted differences between SI values for quercetin could be due to the intracellular accumulation of quercetin during continuous treatment. A weak effect for prophylactic activity of quercetin however, was also observed. These findings suggest that the main anti-dengue activity of quercetin is likely due to its activity against the different stages of intracellular replication of DENV-2 instead of early stages of its replication cycle such as virus attachment or entry. Although, no direct virucidal activity or anti-attachment activity of quercetin was observed in the present study, antiviral activity of quercetin against human cytomegalovirus was reported with $\mathrm{IC}_{50}=3.2 \mu \mathrm{M}$ [13]. Quercetin was also reported to be effective against herpes viruses where it is more specific against HSV-1 with SI $=22$ compared to HSV-2 with SI $=5.7$ [11].

The mechanisms of how quercetin exerts its antiviral effects are not known. However, the effects of other flavonoids against cellular RNA polymerases and formation of the complex with RNA have been reported suggesting that quercetin could also affect the similar replication enzymes [25,26]. Sylimarin, a flavonoid found effective against hepatitis $\mathrm{C}$ virus (HCV), another member of flaviviridae family [27], inhibits virus replication by inhibiting the activity of viral RNA polymerase. In our study, results from the qRT-PCR supported the findings from the viral foci reduction assays that quercetin inhibits DENV-2 replication and the significant reduction in the DENV specific RNA suggests that quercetin may also target the virus replication machinery, namely by inhibiting the RNA polymerase.

Antiviral activity of naringin has been evaluated against few herpesviruses and rotavirus but their reported antiviral activities against HSV-1 and HSV-2 are inconclusive [12,17]. In addition it was reported that naringin did not exhibit any antiviral activity against another RNA virus, sindbis virus [14]. In the present study, the only anti-dengue activity of this flavonoid was demonstrated against adsorption and attachment of virus to the Vero cells and based on its antiviral activity $\left(\mathrm{IC}_{50}=168.2 \mu \mathrm{g} \mathrm{mL}^{-1}\right)$ and its related selectivity index $(\mathrm{SI}=1.3)$, it may not be a good candidate for further development as anti-dengue drug. Similarly, daidzein activity against DENV-2 was not significant compared to quercetin $(S I=1.03)$. Continuous treatment of the infected Vero cells from $5 \mathrm{~h}$ before virus infection up to 4 days post infection did not improve its anti-dengue activity significantly. This compound therefore, could not be a suitable candidate for further development as anti-dengue drug. Hesperetin, the other flavonoid evaluated in our study, did not show no anti-dengue activity in any stages of virus infection and replication processes and this is despite the previously reported antiviral activity of hesperetin against sindbis virus [14]. Therefore, hesperetin is also not recommended for further investigations for anti-dengue drug development. In all our experiments, we showed that $0.5 \%$ of DMSO, the highest concentration of solvent used in the bioflavonoid treatment did not exhibit any antiviral activity against DENV-2 and this eliminated any probable antiviral activity from DMSO.

Findings from our study, suggest that there are select flavonoids including quercetin and fisetin, which are both flavonol, that exhibited significant DENV replication inhibition properties [28]. While the flavonoids in general share common basic molecular base structure, flavone (2-phenyl-1,4-benzopyrone), we showed here that the flavanone, hesperetin, and flavanone glycoside, naringin, showed no significant anti-DENV replication activities. In addition, we had earlier shown that naringenin [28], another flavanone metabolized from naringin and here, daidzein, an isoflavone also had no significant DENV replication inhibition properties. While quercetin was shown here to be effective in inhibiting DENV replication, its glycoside form, rutin (quercetin-3-O-rutinoside) showed no significant inhibition properties [28]. These suggest that while flavonol could be the basic molecule that possesses anti DENV replication properties, specific structural properties of the different flavonol derivatives would have different effects on the efficacy of the compounds against dengue.

The demonstration in vitro that flavonols including quercetin and fisetin possess anti DENV replication properties does not necessarily translate into immediate use of these compounds as antivirals against DENV. Further studies will be needed to demonstrate the antiviral activities of these compounds against different genotypes of dengue virus and in appropriate animal model. 
There is also a need to address the issue of the low bioavailability of quercetin especially for therapeutic use [29-31]. Several strategies to increase the bioavailability of quercetin that include using lipids and emulsifiers, co-crystalization of quercetin or using ester-based precursors have been investigated [32-34]. The other topic of research would be combination drug study. At its current calculated $\mathrm{IC}_{50}$ values, the antiviral efficacy of quercetin can be further improved possibly by combining it with other potential anti-dengue compounds. This is exemplified in a study that reported the synergistic effect of $\alpha$-glucoside in combination with a standard antiviral drug, ribavirin is effective against dengue infection [35].

\section{Conclusions}

In conclusion, the present study demonstrates that the bioflavonoid quercetin exhibited significant anti DENV replication properties. We further showed that quercetin affects intracellular DENV virus replication but not the DENV attachment and entry processes. These results together with the earlier findings reporting the anti DENV properties of fisetin, suggest that these flavonols could be further investigated for their specific uses as candidate anti-DENV therapeutics.

\section{Acknowledgements}

We thank the Ministry of Science, Technology, and Innovation of Malaysia for Malaysia Genome Institute initiative grant 07-05-MGI-GMB015, the Ministry of Higher Education for Long-Term Researcg Grant Scheme (LRGS), LRGS/TD/2011/UM/Penyakit-Berjangkit and University of Malaya Research University Grant.

\section{Author details}

${ }^{1}$ Tropical Infectious Disease Research and Education Center (TIDREC), Department of Medical Microbiology, Faculty of Medicine, University of Malaya, Kuala Lumpur, Malaysia. ${ }^{2}$ Department of Pharmacology, Faculty of Medicine, University of Malaya, Kuala Lumpur, Malaysia.

\section{Authors' contributions}

KZ designed and carried out the antiviral and cytotoxicity studies and drafted the manuscript. BTT carried out the virus propagation and antiviral studies. SSS participated in the quantitative RT-PCR. WPF participated in the design of the study, performed statistical analyses and edited the manuscript. MRM participated in study design and provided all bioflavonoids. SAB conceived the whole study and edited the manuscript. All authors read and approved the final manuscript.

\section{Competing interests}

The authors declare that they have no competing interests.

Received: 11 September 2011 Accepted: 28 December 2011 Published: 28 December 2011

\section{References}

1. Che P, Wang L, Li Q: The development, optimization and validation of an assay for high throughput antiviral drug screening against Dengue virus. Int J Clin Exp Med 2009, 2:363-373.

2. Kwon HJ, Kim HH, Yoon SY, Ryu YB, Chang JS, Cho KO, Rho MC, Park SJ, Lee WS: In vitro inhibitory activity of Alpinia katsumadai extracts against influenza virus infection and hemagglutination. Virol J 2010, 7:307.
3. Yasuhara-Bell J, Yang Y, Barlow R, Trapido-Rosenthal H, Lu Y: In vitro evaluation of marine-microorganism extracts for anti-viral activity. Virol J 2010, 7:182.

4. Zandi K, Taherzadeh M, Yaghoubi R, Tajbakhsh S, Rastian Z, Sartavi K: Antiviral activity of Avicennia marina against herpes simplex virus type 1 and vaccine strain of poliovirus (An in vitro study). J Med Plant Res 2009, 3:771-775

5. Talarico LB, Damonte EB: Interference in dengue virus adsorption and uncoating by carrageenans. Virol 2007, 363:473-485.

6. Laille M, Gerald F, Debitus C: In vitro antiviral activity on dengue virus of marine natural products. Cell Mol Life Sci 1998, 54:167-170.

7. Talarico LB, Pujol CA, Zibetti RG, Faría PC, Noseda MD, Duarte ME, Damonte EB: The antiviral activity of sulfated polysaccharides against dengue virus is dependent on virus serotype and host cell. Antiviral Res 2005, 66:103-110.

8. Parida MM, Upadhyay C, Pandya G, Jana AM: Inhibitory potential of neem (Azadirachta indica Juss) leaves on dengue virus type-2 replication. J Ethnopharmacol 2002, 79:273-8.

9. Ferreres F, Taveira M, Pereira DM, Valentão P, Andrade PB: Tomato (Lycopersicon esculentum) seeds: new flavonols and cytotoxic effect. $J$ Agric Food Chem 2010, 58:2854-61.

10. Zhang Y, Li Y, Cao C, Cao J, Chen W, Zhang Y, Wang C, Wang J, Zhang X, Zhao $X$ : Dietary flavonol and flavone intakes and their major food sources in Chinese adults. Nutr Cancer 2010, 62:1120-7.

11. Chiang LC, Chiang W, Liu MC, Lin CC: In vitro antiviral activities of Caesalpinia pulcherrima and its related flavonoids. J Antimicrob Chemother 2003, 52:194-8

12. Lyu SY, Rhim JY, Park WB: Antiherpetic activities of flavonoids against herpes simplex virus type 1 (HSV-1) and type 2 (HSV-2) in vitro. Arch Pharm Res 2005, 28:1293-301.

13. Evers DL, Chao CF, Wang X, Zhang Z, Huong SM, Huang ES: Human cytomegalovirus-inhibitory flavonoids: studies on antiviral activity and mechanism of action. Antiviral Res 2005, 68:124-34.

14. Paredes A, Alzuru M, Mendez J, Rodriguez-Ortega M: Anti-Sindbis activity of flavanones hesperetin and naringenin. Biol Pharm Bull 2003, 26:108-9.

15. Kim HK, Jeon WK, Ko BS: Flavanone glycosides from Citrus junos and their anti-influenza virus activity. Planta Med 2001, 67:548-9.

16. De Clercq E: Potential antivirals and antiviral strategies against SARS coronavirus infections. Expert Rev Anti Infect Ther 2006, 4:291-302.

17. Kaul TN, Middleton E Jr, Ogra PL: Antiviral effect of flavonoids on human viruses. J Med Virol 1985, 15:71-9.

18. Liu AL, Wang HD, Lee SM, Wang YT, Du GH: Structure-activity relationship of flavonoids as influenza virus neuraminidase inhibitors and their in vitro anti-viral activities. Bioorg Med Chem 2008, 16:7141-7.

19. Okuno $Y$, Fukunaga $T$, Srisupaluck S, Fukai K: A modified PAP (peroxidaseanti-peroxidase) staining technique using sera from patients with dengue hemorrhagic fever (DHF): 4 step PAP staining technique. Biken J 1979, 22:131-5.

20. Wong SS, Abd-Jamil J, Abubakar S: Antibody neutralization and viral virulence in recurring dengue virus type 2 outbreaks. Viral Immunol 2007, 20:359-68.

21. Seah CL, Chow VT, Tan HC, Can YC: Rapid, single-step RT-PCR typing of dengue viruses using five NS3 gene primers. J Virol Methods 1995 51:193-200.

22. Sanchez I, Gomez-Garibay F, Taboada J, Ruiz BH: Antiviral effect of flavonoids on the dengue virus. Phytother Res 2000, 14:89-92.

23. Muhamad M, Kee LY, Rahman NA, Yusof R: Antiviral actions of flavanoidderived compounds on dengue virus type-2. Int J Biol Sci 2010, 6:294-302.

24. Kiat TS, Pippen $R$, Yusof R, Ibrahim H, Khalid N, Rahman NA: Inhibitory activity of cyclohexenyl chalcone derivatives and flavonoids of fingerroot, Boesenbergia rotunda (L.), towards dengue-2 virus NS3 protease. Bioorg Med Chem Lett 2006, 16:3337-40.

25. Shinozuka K, Kikuchi Y, Nishino C, Mori A, Tawata S: Inhibitory effect of flavonoids on DNA-dependent DNA and RNA polymerases. Experientia $1988,44: 882-5$

26. Nafisi Sh, Shadaloi A, Feizbakhsh A, Tajmir-Riahi HA: RNA binding to antioxidant flavonoids. J Photochem Photobiol B 2009, 94:1-7.

27. Wagoner J, Negash A, Kane OJ, Martinez LE, Nahmias Y, Bourne N, Owen DM, Grove J, Brimacombe C, McKeating JA, Pécheur El, Graf TN, Oberlies NH, Lohmann V, Cao F, Tavis JE, Polyak SJ: Multiple effects of silymarin on the hepatitis C virus lifecycle. Hepatology 2010, 51:1912-1921. 
28. Zandi K, Teoh BT, Sam SS, Wong PF, Mustafa MR, Abubakar S: In vitro antiviral activity of fisetin, rutin and naringeninagainst dengue virus type-2. J Med Plants Res 2011, 5:5534-5539.

29. Graefe EU, Wittig J, Mueller S, Riethling AK, Uehleke B, Drewelow B, Pforte $H$, Jacobasch G, Derendorf $H$, Veit M: Pharmacokinetics and bioavailability of quercetin glycosides in humans. J Clin Pharmacol 2001, 41:492-9.

30. Kim MK, Park KS, Lee C, Park HR, Choo H, Chong Y: Enhanced Stability and Intracellular Accumulation of Quercetin by Protection of the Chemically or Metabolically Susceptible Hydroxyl Groups with a Pivaloxymethyl (POM) Promoiety. J Med Chem 2010, 53:8597-8607.

31. D'Archivio M, Filesi C, Varì R, Scazzocchio B, Masella R: Bioavailability of the polyphenols: status and controversies. Int J Mol Sci 2010, 31:1321-1342.

32. Azuma K, Ippoushi K, Ito H, Higashio H, Terao J: Combination of lipids and emulsifiers enhances the absorption of orally administered quercetin in rats. J Agric Food Chem 2002, 50:1706-1712.

33. Smith AJ, Kavuru P, Wojtas L, Zaworotko MJ, Shytle RD: Cocrystals of quercetin with improved solubility and oral bioavailability. Mol Pharm 2011, 8:1867-1876.

34. Biasutto L, Marotta E, De Marchi U, Zoratti M, Paradisi C: Ester-based precursors to increase the bioavailability of quercetin. J Med Chem 2007, 50:241-253.

35. Chang J, Schul W, Butters TD, Yip A, Liu B, Goh A, Lakshminarayana SB, Alonzi D, Reinkensmeier G, Pan X, Qu X, Weidner JM, Wang L, Yu W, Borune N, Kinch MA, Rayahin JE, Moriarty R, Xu X, Shi PY, Guo JT, Block TM: Combination of a-glucosidase inhibitor and ribavirin for the treatment of dengue virus infection in vitro and in vivo. Antiviral Res 2011, 89:26-34.

doi:10.1186/1743-422X-8-560

Cite this article as: Zandi et al: Antiviral activity of four types of bioflavonoid against dengue virus type-2. Virology Journal 2011 8:560.

\section{Submit your next manuscript to BioMed Central and take full advantage of:}

- Convenient online submission

- Thorough peer review

- No space constraints or color figure charges

- Immediate publication on acceptance

- Inclusion in PubMed, CAS, Scopus and Google Scholar

- Research which is freely available for redistribution

Submit your manuscript at www.biomedcentral.com/submit 